\title{
Nanomedicine: Tiny Particles and Machines, from Diagnosis to Treatment of Cardiovascular Disease, Provides Huge Achievements
}

\author{
Md. Ismail1 ${ }^{1}$, Md. Faruk Hossain ${ }^{2}$, Md. Fazlul Karim³ ${ }^{3}$, Hossain Uddin Shekhar ${ }^{{ }^{*}}$ \\ ${ }^{1}$ Department of Biochemistry and Molecular Biology, University of Dhaka, Dhaka, Bangladesh \\ ${ }^{2}$ Department of Biological Sciences, St John's University, New York, USA \\ ${ }^{3}$ Department of Biological Sciences, Eastern Illinois University, Charleston, USA \\ Email: hossainushekhar@gmail.com
}

Received 16 June 2015; accepted 21 September 2015; published 24 September 2015

Copyright (C) 2015 by authors and Scientific Research Publishing Inc.

This work is licensed under the Creative Commons Attribution International License (CC BY). http://creativecommons.org/licenses/by/4.0/

c) (i) Open Access

\begin{abstract}
Cardiovascular disease is one of many reverberating ailments that affect and kill hundreds of thousands of people around the world. To date treatments that offer improvement in the health condition of diseased people include the most promising nanomedicine although it is in its infancy, yet attaining attention from researchers of top notch day by day. In this current review importance is given on the application of nanomedicine in the diagnosis as well as treatment of cardiovascular disease.
\end{abstract}

Keywords

Nanomedicine, Cardiovascular Disease, Diagnosis, Treatment

\section{Introduction}

Technological application of nanometer sized molecule in medicine with the purpose of fighting and curing ailments is by default the definition of nanomedicine [1]. Currently, nanomedicine is a rapidly-flourishing as well as hectic sector of research activity that attains the focus of researchers of top notch reputation around the globe. In order to get rid of many present challenges in the treatment of cardiovascular, cancer as well as many other diseases, nanomedicines provide excellent solutions by virtue of its unique characteristics [2]-[8]. Cardiovascu-

*Corresponding author.

How to cite this paper: Ismail, Md., Hossain, Md.F., Karim, Md.F. and Shekhar, H.U. (2015) Nanomedicine: Tiny Particles and Machines, from Diagnosis to Treatment of Cardiovascular Disease, Provides Huge Achievements. Advances in Bioscience and Biotechnology, 6, 613-623. http://dx.doi.org/10.4236/abb.2015.69064 
lar disease (CVD) is the name of a forerunner ailment that inflicts and kills millions of people around the globe and is expected to be continued as one of the top most indorsers to healthcare expenditure. The stronghold of CVD is the developed countries, but, it is also disseminating with a quick pace, among developing countries of the world. Information from World Health Organization (WHO) validates this claim, which states that approximately 17 million people's lives have been snatched away by CVD each year throughout the world [9]. Mostly attributed to the significant developments in surgical interventions, diagnostics and consciousness as well as concomitant lifestyle amendments, cardiovascular-related morbidity and mortality, in a time frame of 30 years in the later parts of the twentieth century, have resulted in a more than twofold reduction [10] [11]. The unconscionable number of cardiovascular diseases-related morbidity and mortality is thought to be the reason, behind the pressing requirement of more efficacious schemes to ameliorate the patient's condition. The last most prominent breakthrough in technology to affect CVD took place over a decade ago when Palmaz \& Schatz introduced coronary stent which got its approval from the FDA in 1994. Since then, the new smash hit curatives (statins, beta blockers, and etc.) and the subtleties of surgical processes, have become the hallmark of reliance. But now the emerging and ever evolved nanomedicine is expected to confront and deal efficiently the present challenges in cardiovascular disease as well as to bring about a breakthrough in the identification and treatment of cardiovascular disease effectively (Figure 1). In this review, our discussion is related to the recent developments in the arena of nanobiotechnology for the diagnosis and treatment of cardiovascular disease, in light of nanoparticles, ex vivo biomarkers, in vivo sensors and programmable bio-nanochip (P-BNC) system for the diagnosis purpose as well as in light of theranostic and therapeutic nanoparticles, innovative liposomal platforms and tissue regenerating devices for the treatment purpose of cardiovascular disease.

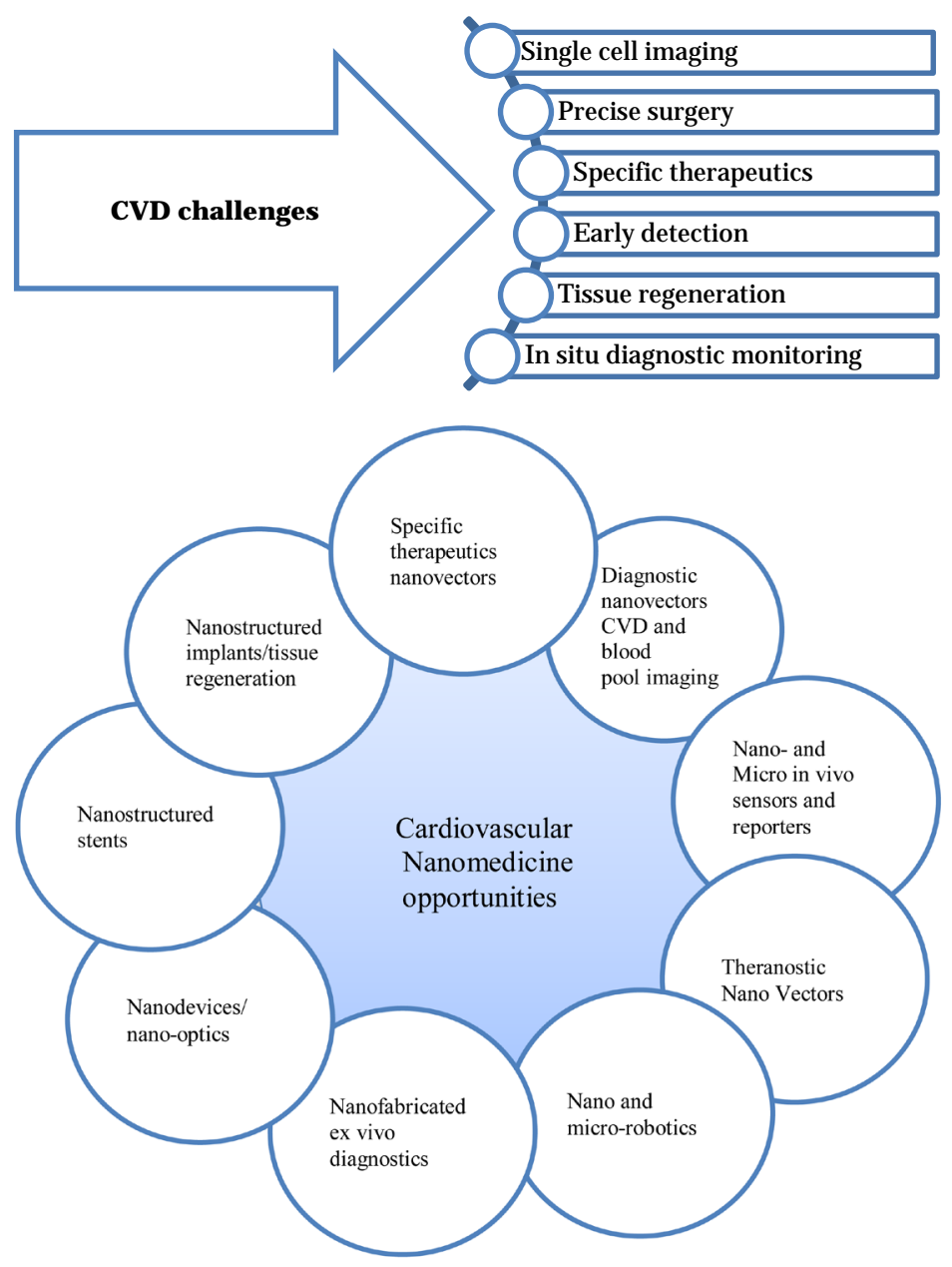

Figure 1. Outline of challenges in diagnosis and treatment of CVD and scopes to intervene with nanomedicine. 


\section{Nanomedicine in the Diagnosis of Cardiovascular Disease}

\subsection{Advanced and Sophisticated Diagnosis of CVD with Nanoparticles}

A bulk number of drug delivery systems based on particles of nanometer size have recently been evolved, with variegated features and multiple functionalities [12]-[15] showing variegations in 1) sizes 2) shapes and 3) surface functionalization. Identification and characterization of initial disease stages before the appearance of gross disease manifestations, are the abilities of multifaceted nanoscale contrast agents. Nanoparticles that have the capacity to generate contrast, can be useful in cardiovascular imaging. Paramagnetic, fluorescent and other particles are contrast generating nanoparticles those can be used in the detection as well as characterization of initial ailment stages before the disease become more conspicuous and fatal. Internal structures images are now obtainable in which process there is a prerequisite of certain radiofrequency waves as well as magnetic fields in magnetic resonance imaging (MRI) mediated cardiovascular imaging. The sole purpose of using contrast agents is to magnify the subtle changes in the energy level of tissues in MRI. Gadolinium-diethylenetriaminopentaacetic acid is an example of a paramagnetic contrast agent which provides a bright contrast in MR images [16] [17]. A recent example of T1 enhancing contrast agent is manganese nanoparticles [18]. An eminent example of nanoparticles that can give off light is quantum dots. Quantum dots are special types of nanoparticle having fluorescence within itself. There is a positive correlation between an increase in particle size and an increase in emission wavelength [19]. For imaging purpose, micro particle-based contrast molecules are in use and example of this includes porous silicon particles which have encapsulated iron oxide nanoparticle. Improvement in contrast, has come from this iron oxide nanoparticle [20]. Macrophages engulf these multistage particles through phagocytosis, hence providing the chance of imaging of inflamed portions where macrophages aggregate [21]. An example of this macrophage aggregation is atherosclerotic plaque. Multimodal imaging is not an illusion, rather an assertion in the age of nanoscience, where nanoparticles have more than one contrast agents [22]-[24]. An illustrious example of these types of molecule is 18F-CLIO (18F-cross-linked iron oxide). Markers of angiogenesis, macrophages [25], collagen III [26], as well as fibrin [27] all together are important in atherosclerotic plaque image targeting. Plaque rupture provides many signals and one of the earliest signals is fibrin deposition. Through ultrasound [28] and magnetic resonance imaging [29] arterial thrombi can be imaged by targeting fibrin and other tissue factor. Specific interaction between nanoparticles conjugated to ligands and $\alpha \mathrm{v} \beta 3$-integrin can be exploited in angiogenesis targeting [30]. In MRI and computed tomography (CT) various contrast agents, for instance iodine can be carried within nanoliposomes and the benefit is that the contrast agents have a significant reduction in body clearance, ameliorating potentialities of blood as well as cardiac imaging in study models [31] [32].

\subsection{CVD Diagnosis with Programmable Bio-Nanochips (P-BNCs)}

Assessment of CVD in quick time and in a reliable way is the prerequisite of point-of-care treatment, where the clinicians can have significant relief in discharging personnel with benign etiology while giving proper treatment to CVD inflicted personnel. Hence the scheme termed programmable bio-nanochip (P-BNC), a novel medical device with the potentiality of providing high functioning as well as trimmed cost, comes under light. The capacity to immediately ensure sensitive, authentic simultaneous assessment of multiple prime biomarkers of cardiology at the point-of-care pledges to change the scenario of clinical nosology. To attain this target, researchers have worked to ameliorate the present state of point-of-care IVD through the improvement, substantiation, as well as the effectuation of P-BNCs [33]-[40]. Programmable bio-nanochips gets its name from its ability to work when reprogrammed while maintaining standard platform in assessing the bio-markers affiliated with specific ailments. High performance at reduced cost is possible if the similarity between microelectronics industry and the ability to mass-produce the sensor elements, can be maintained, where the "chip" term emphasizes. It contains incorporated nano-nets and quantum dots for the purpose of efficacious and instant biomarker capture and augmented signal development respectively. P-BNCs provide output within minutes while methods like ELISA (enzyme-linked immunoassay) provide output within hours. P-BNCs have detection capacity in more magnitude lower than the traditional. Researchers have found that saliva has got many biomarkers of acute myocardial infarction diagnosis [41] and best 10 biomarkers with the most significant information are tumor necrosis factor-alpha (TN F- $\alpha$ ), C-reactive protein (CRP), RANTES, soluble intercellular adhesion molecule-1 (sICAM-1), myeloperoxidase (MPO), myoglobin (MYO), matrix metalloproteinase-9 (MMP-9), interleukin-1 beta (IL-1 $\beta$ ), adiponectin, and soluble CD40 Ligand (sCD40L) [42] [43]. 


\subsection{Ex Vivo Biomarkers for CVD Diagnosis}

Individual biomarkers of CVD that have drawn the attention of researchers include the levels of, fibrinogen [44], D-dimer [45], B-type natriuretic peptide [46], C-reactive protein [47], as well as homocysteine [48] for the identification of high-risk population. To specifically select low molecular weight proteins, nanoporous materials can be useful because they can monitor as well as find new circulating biomarkers in body fluids [49] [50]. $\mathrm{pH}$ variations measurement, detection of small quantity of molecules, whether chemical or biological, all are possible with the advent of nanowires [51]. Myoglobin, CK-MB (creatine kinase MB isoenzyme), and cardiac troponins have got FDA approval, so automatically they are in the focus of commercial cardiac biomarker pointof-care devices [52] [53]. Troponin antibodies and nickel nanohairs have been combined with modified viral nanoparticles to identify troponin in serum where the identification limit of troponin is six to seven orders of magnitude lower than traditional immunological assays [54].

\subsection{In Vivo Sensors in CVD Diagnosis}

In situ quick identification of ions such as, $\mathrm{H}^{+}, \mathrm{Na}^{+}, \mathrm{K}^{+}$and $\mathrm{Ca}^{2+}$ have been possible through the development of nanosensors. $\mathrm{H}^{+}$and $\mathrm{K}^{+}$ion activity can serve as an important marker in case of acute myocardial infarction onset [55]. Analysis at in vivo is possible because nanosensors have been implanted in epicardial and the arterial region [56]. Field effect transistors (FET) technology has already been exploited for the development of a silicon needle with multi-nanosensor for the identification of myocardial infarction [57]. Real-time detection of $\mathrm{Ca}^{2+}$ ions is also possible, through functionalized nanowires [51]. Shin KH, et al. [58] described the in-vitro development of bio-MEMS pressure sensors which can be used for the purpose of in-situ assessment of blood pressure. Kim J-H, et al. [59] described the development of near-infrared fluorescence sensors for NO with singlewalled carbon nanotube technology.

\section{Nanomedicine in the Treatment of Cardiovascular Disease}

\subsection{Intervention in Cardiovascular Disease with Liposome}

Delivery of therapeutics to targeted tissues is possible through the design and construction of nanoscale particles while reduced toxicity as well as higher efficiency is obtainable [60] [61]. Liposomes have huge skillfulness with regard to physicochemical characteristics, permitting acclimatization of this tiny particle to dovetail to the exact application in biology [62]. Liposomes circulatory half life has been extended through the emergence of polyethylene glycol (PEG) which assist in the avoidal of phagocytic cells of the body. Coupling of liposomes with peptides or proteins for increased targeting to specific tissues is also possible [63] [64]. Although initiatives have been carried out to exploit the benefits of liposomal approach but currently, there are no approved liposomal formulations for the treatment of CVD in human. In an attempt to treat chronic myocardial ischemia, during angioplasty and stenting, Hedman et al. [65] delivered vascular endothelial growth factor encoding plasmid through liposomes, with the aim to prevent in-stent restenosis and postangioplasty but the treatment doomed to change the incidence of restenosis, while it was demonstrated that gene transfer using liposomes was a viable and well tolerated approach. In a different clinical trial paclitaxel nanoparticles fixed to albumin was used to prevent in-stent restenosis. Reports claimed that without major complication the innovative approaches were well tolerated at 10 or $30 \mathrm{mg} / \mathrm{m}^{2}$ [66] [67]. Zhang et al. [68] described acquirement of the surface modified liposome with peptide which has an arginine-rich sequence (CRPPR) to coronary endothelial in myocardial infarction and ischemia models. In comparison to nontargeted liposomes, the CRPPR-conjugated nanostructure attains a 47-fold increase in accruement in the injured tissue vasculature. It is worth mentioning that healthy tissue vasculature has accruement to a lesser extent. Modified liposomes can be used to minimize accidental or unwanted damage, to tissues that are healthy and adjacent, after myocardial infarction by reducing inflammatory responses from macrophages. Macrophages exist at the nearby area of infarction and thus can serve as the basis for cell-based targets for therapy. Modified liposomes have been developed by Harel-Adar et al. [69] that have surface phosphatidylserine (PS). Apoptotic cells surface phosphatidylserine act as a trigger to initiate the inflammatory circuit of macrophages. Phosphatidylserine containing surface attenuated liposomes upon engulfment by macrophages brings in the release of more anti-inflammatory cytokines, upregulation of CD206 as well as the accompaniment of TNF-alpha and CD86 downregulation. Fabricated fluorescent PEGylated liposome has the ability to distribute therapeutics to the infarcted heart [70]. Liposomes loaded with oligodextran surfactants 
as well as RGD can serve the purpose of targeted delivery and reduced RES uptake, respectively [71]. The surfactants of oligosaccharide class imitate cell glycocalyx of restricted opsonization, resulting in reduced RES uptake [72]. Research activity of Lestini et al. validated the surreptitious nature through which liposomes can reduce opsonization and RES clearance. Activated platelets have P-selectin on their surface which is the target of glycoliposomes with negative charge [73]. This delivery system exploited the imitation properties of activated leukocytes of containing P-selectin glycoprotein ligand 1 in order to ease the specific attachment between P-selec- tin receptor on activated platelets and liposomes of the target. TMR-484 is a special liposomal formulation of prednisolone, developed by Joner et al. [74]. The injury site high with chondroitin sulfate proteoglycans, which can bind with great affinity with prednisolone. After 24 hours of administration, reports claimed, the lesion had liposome concentration that had increased by 100 -fold in comparison to nonstented arteries, when tested in a laboratory animal model of atheroma. Solubilization of aggregated cholesterol in atherosclerosis is one of the approaches to the treatment of atherosclerosis. Liposomes loaded with phosphatidylcholine (PC) were developed by Cho et al. [75] with the purpose of lesion enrichment with high-density lipoprotein (HDL). The process of atherosclerosis includes the accumulation and subsequent oxidization of LDL in the artery wall and finally their picked up by foam cells. HDL can limit the process of inflammation that leads to atherosclerosis. Liposomal phosphatidylcholine could be a good therapy choice for the regression of atherosclerotic plaque because cholesterol-fed rabbits have undergone infusion of liposomal formulations and have resulted in a reduced cholesterol content as well as atherosclerotic plaque volume in the aortic walls. Activated macrophages have been shown to be attracted by liposomal components in atheroma components that are metabolically active. The liposome platform contained, nanogold, lipoprotein-associated phospholipase A2 and rhodamine, which has a surface potential of negative value. Walton et al. [76] demonstrated that in lesion of rabbits with Watanabe heritable hyperlipidemia have positive macrophage targeting, which has been assured through transmission electron microscopy, that have indicated the presence of liposome in high amount within the atheromas and the basis of identification was nanogold component.

\subsection{Nanoparticles with Theranostic and Therapeutic Properties}

Drugs that are cytotoxic in nature and can prevent smooth muscle cell growth are being in use to inhibit restenosis. Example of these drugs includes etoposides, paclitaxel, doxorubicin etc. Immunomodulators or inflammatory response inhibitory molecules like Cyclosporine A, steroids etc. and platelet derived growth factor receptor antagonists are also in use of preventing restenosis. Encapsulation of these therapeutic molecules in nanoparticles gives sanctuary from degradation of enzymes as well as permit sustained release profile [77] [78]. As an important advancement in drug delivery, there is a growing interest for theranostic agents [79]. Treatment results and therapeutic molecules, both of them can be precisely observed through the combination of therapeutic nanoparticle and diagnostic imaging modality. Theranostic nanoparticles imaging abilities can serve numerous purpose, including the verification of the delivery of specific molecules to its target, designing of dose patterns, as well as identification of personnel who either respond or not responding in a specifically designed therapy. For instance in hyperlipidemic animals a sustained antiangiogenesis therapy was carried out through the use of theranostic $\alpha \mathrm{v} \beta 3$-integrin targeted paramagnetic nanoparticles. Data from MRI studies has proven a decline (between 50\% and 75\%) in neovascular signal for 21 days. Histological evaluation was acceptable. These outcomes have pointed towards the broad window of this strategy for efficacious therapy that is antiangiogenic in nature [80] [81].

\subsection{Nanomedicine in Tissue Regeneration Devices}

Nanotechnology finds itself in the field of cardiovascular device development and research and it has already devoted itself to the improvement of stent technology. Narrowing of the blood vessel is termed as stenosis, which hamper normal blood flow. The mainstream challenges in using stents in an initiative of revascularization of the narrowed arteries are in-stent restenosis that results from intimal hyperplasia [82] as well as activated platelets mediated thrombosis in the later stage [83]. Establishment of the stent as the drug delivery platform is the following degree of device sophistication. Johnson \& Johnson, Guidant, Boston Scientific as well as Medtronic are the industry giants that started the production of drug eluting stents (DES) which are illustrious for releasing drugs, for instance sirolimus as well as paclitaxel for the exploitation of their anti-proliferative benefits. Drug eluting stents have manifested lower occurrence of restenosis after six months of procedure in comparison 
to their usual counterparts (metal), but recent long term sophisticated researches have raised concerns about whether DES can deliver long term benefits or not [84]-[87]. Incorporation of stent within the vessel wall is possible just because of the fact that the eluted drugs are anti-proliferative in character. Cell cycle inhibition results from eluted drugs that suppress the proliferation. As a result the normal vessel cannot remodel themselves. Incomplete neonatal coverage causes exposure of stent structure that leads to the formation of a thrombus, which is very fatal and complicated even results in increased death that can be attributed to the thrombosis of later stage. This whole scenario usually occurs if there is a premature surcease of dual antiplatelet therapy [85] [86]. Currently, researchers are trying to deliver tacrolimus [88] by exploiting the ability of aluminum oxide stent surfaces. Paclitaxel elution by using matrixes of carbon-carbon nanomaterials has also been attempted [89]. Nanoporous $\mathrm{TiO}_{2}$ films have been tested for various drug delivery [90]. Inflicted vessels problem can be solved by increasing the interaction between endothelial cells and stent surfaces, while stents provide the platform of revascularization process. This enhancement in interaction exploits surface nanotexturing. Vascular tissue has specific structures and imitation of this structure is possible, for improving the adhesion of cells, through nanoscale topography on hydroxyapatite substrates [91] and nickel titanium [83]. Afterwards there is an increased endothelialization of the stent and decreased thrombosis [92].

\section{Conclusion}

Transcending expansion and understanding of sectors like molecular biology, material science, genetics, cellular biology, bioengineering and proteomics construct nanobiotechnology which acts as a fixative to connect the dots, between interactions on the microscopic and molecular levels, to form an outstanding and inclusive platform from where it can become the major potential actors in the race towards the progress of CVD diagnosis and treatment. Scientists have made us optimistic about nanomedicine with their outstanding research outcomes. The day is not so far when, currently seeming fledgling, nanomedicine will become the hegemon in the diagnosis and treatment of cardiovascular disease.

\section{Conflict of Interests}

The authors declare that there is no conflict of interests regarding the publication of this paper.

\section{References}

[1] Kim, B.Y.S., Rutka, J.T. and Chan, W.C.W. (2010) Nanomedicine. New England Journal of Medicine, 363, 24342443. http://dx.doi.org/10.1056/NEJMra0912273

[2] Bharali, D.J. and Mousa, S.A. (2010) Emerging Nanomedicines for Early Cancer Detection and Improved Treatment: Current Perspective and Future Promise. Pharmacology \& Therapeutics, 128, 324-335. http://dx.doi.org/10.1016/j.pharmthera.2010.07.007

[3] Sajja, H.K., East, M.P., Mao, H., Wang, Y.A., Nie, S. and Yang, L. (2009) Development of Multifunctional Nanoparticles for Targeted Drug Delivery and Noninvasive Imaging of Therapeutic Effect. Current Drug Discovery Technologies, 6, 43-51. http://dx.doi.org/10.2174/157016309787581066

[4] Ledet, G. and Mandal, T.K. (2012) Nanomedicine: Emerging Therapeutics for the 21st Century. U.S. Pharmacist, 37, 7-11.

[5] Godin, B., Sakamoto, J.H., Serda, R.E., Grattoni, A., Bouamrani, A. and Ferrari, M. (2010) Emerging Applications of Nanomedicine for the Diagnosis and Treatment of Cardiovascular Diseases. Trends in Pharmacological Sciences, 31, 199-205. http://dx.doi.org/10.1016/j.tips.2010.01.003

[6] Chhatriwalla, A.K. and Bhatt, D.L. (2008) Should Dual Antiplatelet Therapy after Drug-Eluting Stents Be Continued for More Than 1 Year? Circulation Cardiovascular Interventions, 1, 217-225. http://dx.doi.org/10.1161/CIRCINTERVENTIONS.108.811380

[7] Galvin, P., Thompson, D., Ryan, K.B., McCarthy, A., Moore, A.C., Burke, C.S., et al. (2012) Nanoparticle-Based Drug Delivery: Case Studies for Cancer and Cardiovascular Applications. Cellular and Molecular Life Sciences, 69, 389-404. http://dx.doi.org/10.1007/s00018-011-0856-6

[8] Bhaskar, S., Tian, F., Stoeger, T., Kreyling, W., de la Fuente, J.M., Grazú, V., et al. (2010) Multifunctional Nanocarriers for Diagnostics, Drug Delivery and Targeted Treatment Across Blood-Brain Barrier: Perspectives on Tracking and Neuroimaging. Particle and Fibre Toxicology, 7, 3. http://dx.doi.org/10.1186/1743-8977-7-3

[9] World Health Organization (2011) Programmes and Projects: Global Atlas on Cardiovascular Disease Prevention and 
Control. World Health Organization, Geneva. http://www.who.int/cardiovascular_diseases/en/

[10] Hoyert, D. and Xu, J. (2012) Deaths: Preliminary Data for 2011. National Vital Statistics Reports. National Center for Health Statistics, Hyattsville, 61, 1-65.

[11] Jemal, A., Siegel, R., Ward, E., Hao, Y., Xu, J. and Thun, M.J. (2009) Cancer Statistics, 2009. CA: A Cancer Journal for Clinicians, 59, 225-249. http://dx.doi.org/10.3322/caac.20006

[12] Riehemann, K., Schneider, S.W., Luger, T.A., Godin, B., Ferrari, M. and Fuchs, H. (2009) Nanomedicine-Challenge and Perspectives. Angewandte Chemie International Edition, 48, 872-897. http://dx.doi.org/10.1002/anie.200802585

[13] Peer, D., Karp, J.M., Hong, S., Farokhzad, O.C., Margalit, R. and Langer, R. (2007) Nanocarriers as an Emerging Platform for Cancer Therapy. Nature Nanotechnology, 2, 751-760. http://dx.doi.org/10.1038/nnano.2007.387

[14] Ferrari, M. (2008) Nanogeometry: Beyond Drug Delivery. Nature Nanotechnology, 3, 131-132. http://dx.doi.org/10.1038/nnano.2008.46

[15] Ferrari, M. (2005) Cancer Nanotechnology: Opportunities and Challenges. Nature Reviews Cancer, 5, 161-171. http://dx.doi.org/10.1038/nrc1566

[16] Smith, R.C. and McCarthy, S. (1992) Physics of Magnetic Resonance. Journal of Reproductive Medicine, 37, 19-26.

[17] Sosnovik, D.E., Nahrendorf, M. and Weissleder, R. (2008) Magnetic Nanoparticles for MR Imaging: Agents, Techniques and Cardiovascular Applications. Basic Research in Cardiology, 103, 122-130. http://dx.doi.org/10.1007/s00395-008-0710-7

[18] Pan, D., Senpan, A., Caruthers, S.D., Williams, T.A., Scott, M.J., Gaffney, P.J., et al. (2009) Sensitive and Efficient Detection of Thrombus with Fibrin-Specific Manganese Nanocolloids. Chemical Communications, 3234-3236. http://dx.doi.org/10.1039/b902875g

[19] Michalet, X., Pinaud, F.F., Bentolila, L.A., Tsay, J.M., Doose, S., Li, J.J., et al. (2005) Quantum Dots for Live Cells, in Vivo Imaging, and Diagnostics. Science, 307, 538-544. http://dx.doi.org/10.1126/science.1104274

[20] Serda, R.E., Godin, B., Tasciotti, E., Liu, X. and Ferrari, M. (2009) Mitotic Trafficking of Silicon Microparticles. Nanoscale, 1, 250-259. http://dx.doi.org/10.1039/b9nr00138g

[21] Kooi, M.E., Cappendijk, V.C., Cleutjens, K.B., Kessels, A.G., Kitslaar, P.J., Borgers, M., et al. (2003) Accumulation of Ultrasmall Superparamagnetic Particles of Iron Oxide in Human Atherosclerotic Plaques Can Be Detected by in Vivo Magnetic Resonance Imaging. Circulation, 107, 2453-2458. http://dx.doi.org/10.1161/01.CIR.0000068315.98705.CC

[22] Devaraj, N.K., Keliher, E.J., Thurber, G.M., Nahrendorf, M. and Weissleder, R. (2009) 18F Labeled Nanoparticles for in Vivo PET-CT Imaging. Bioconjugate Chemistry, 20, 397-401. http://dx.doi.org/10.1021/bc8004649

[23] Nahrendorf, M., Zhang, H., Hembrador, S., Panizzi, P., Sosnovik, D.E., Aikawa, E., et al. (2008) Nanoparticle PET-CT Imaging of Macrophages in Inflammatory Atherosclerosis. Circulation, 117, 379-387. http://dx.doi.org/10.1161/CIRCULATIONAHA.107.741181

[24] Chen, W., Vucic, E., Leupold, E., Mulder, W.J., Cormode, D.P., Briley-Saebo, K.C., et al. (2008) Incorporation of an apoE-Derived Lipopeptide in High-Density Lipoprotein MRI Contrast Agents for Enhanced Imaging of Macrophages in Atherosclerosis. Contrast Media \& Molecular Imaging, 3, 233-242. http://dx.doi.org/10.1002/cmmi.257

[25] Amirbekian, V., Lipinski, M.J., Briley-Saebo, K.C., Amirbekian, S., Aguinaldo, J.G., Weinreb, D.B., et al. (2007) Detecting and Assessing Macrophages in Vivo to Evaluate Atherosclerosis Noninvasively Using Molecular MRI. Proceedings of the National Academy of Sciences of the United States of America, 104, 961-966. http://dx.doi.org/10.1073/pnas.0606281104

[26] Cyrus, T., Abendschein, D.R., Caruthers, S.D., Harris, T.D., Glattauer, V., Werkmeister, J.A., et al. (2006) MR Three-Dimensional Molecular Imaging of Intramural Biomarkers with Targeted Nanoparticles. Journal of Cardiovascular Magnetic Resonance, 8, 535-541. http://dx.doi.org/10.1080/10976640600580296

[27] Botnar, R.M., Buecker, A., Wiethoff, A.J., Parsons Jr., E.C., Katoh, M., Katsimaglis, G., et al. (2004) In Vivo Magnetic Resonance Imaging of Coronary Thrombosis Using a Fibrin-Binding Molecular Magnetic Resonance Contrast Agent. Circulation, 110, 1463-1466. http://dx.doi.org/10.1161/01.CIR.0000134960.31304.87

[28] Lanza, G.M., Trousil, R.L., Wallace, K.D., Rose, J.H., Hall, C.S., Scott, M.J., et al. (1998) In Vitro Characterization of a Novel, Tissue-Targeted Ultrasonic Contrast System with Acoustic Microscopy. The Journal of the Acoustical Society of America, 104, 3665-3672. http://dx.doi.org/10.1121/1.423948

[29] Morawski, A.M., Winter, P.M., Crowder, K.C., Caruthers, S.D., Fuhrhop, R.W., Scott, M.J., et al. (2004) Targeted Nanoparticles for Quantitative Imaging of Sparse Molecular Epitopes with MRI. Magnetic Resonance in Medicine, 51, 480-486. http://dx.doi.org/10.1002/mrm.20010

[30] Winter, P.M., Morawski, A.M., Caruthers, S.D., Fuhrhop, R.W., Zhang, H., Williams, T.A., et al. (2003) Molecular Imaging of Angiogenesis in Early-Stage Atherosclerosis with Alpha(v) Beta3-Integrin-Targeted Nanoparticles. Circu- 
lation, 108, 2270-2274. http://dx.doi.org/10.1161/01.CIR.0000093185.16083.95

[31] Kao, C.Y., Hoffman, E.A., Beck, K.C., Bellamkonda, R.V. and Annapragada, A.V. (2003) Long-Residence-Time Nano-Scale Liposomal Iohexol for X-Ray-Based Blood Pool Imaging. Academic Radiology, 10, 475-483. http://dx.doi.org/10.1016/S1076-6332(03)80055-7

[32] Mukundan Jr., S., Ghaghada, K.B., Badea, C.T., Kao, C.Y., Hedlund, L.W., Provenzale, J.M., et al. (2006) A Liposomal Nanoscale Contrast Agent for Preclinical CT in Mice. American Journal of Roentgenology, 186, 300-307. http://dx.doi.org/10.2214/AJR.05.0523

[33] Christodoulides, N., Dharshan, P., Wong, J., Floriano, P.F., Neikirk, D. and McDevitt, J.T. (2007) A Microchip-Based Assay for Interleukin-6. Methods in Molecular Biology, 385, 131-144. http://dx.doi.org/10.1007/978-1-59745-426-1_10

[34] Goodey, A., Lavigne, J.J., Savoy, S.M., Rodriquez, M.D., Curey, T., Tsao, A., et al. (2001) Development of Multianalyte Sensor Arrays Composed of Chemically Derivitized Polymeric Microspheres Localized in Micromachined Cavities. Journal of the American Chemical Society, 123, 2559-2570. http://dx.doi.org/10.1021/ja003341l

[35] Christodoulides, N., Tran, M., Floriano, P.N., Rodriquez, M., Goodey, A., Ali, M., et al. (2002) A Microchip-Based Multianalyte Assay System for the Assessment of Cardiac Risk. Analytical Chemistry, 74, 3030-3036. http://dx.doi.org/10.1021/ac011150a

[36] Ali, M.F., Kirby, R., Goodey, A.P., Rodriguez, M.D., Ellington, A.D., Neikirk, D.P., et al. (2003) DNA Hybridization and Discrimination of Singlenucleotide Mismatches Using Chip-Based Microbead Arrays. Analytical Chemistry, 75, 4732-4739. http://dx.doi.org/10.1021/ac034106z

[37] Jokerst, J.V., Raamanathan, A., Christodoulides, N., Floriano, P.N., Pollard, A.A., Simmons, G.W., et al. (2009) Nano-Bio-Chips for High Performance Multiplexed Protein Detection: Determinations of Cancer Biomarkers in Serum and Saliva Using Quantum Dot Bioconjugate Labels. Biosensors and Bioelectronics, 24, 3622-3629. http://dx.doi.org/10.1016/j.bios.2009.05.026

[38] Lavigne, J.J., Savoy, S., Clevenger, M.B., Ritchie, J.E., McDoniel, B., Yoo, S.J., et al. (1998) Solution-Based Analysis of Multiple Analytes by a Sensor Array: Toward the Development of an "Electronic Tongue". Journal of the American Chemical Society, 120, 6429-6430. http://dx.doi.org/10.1021/ja9743405

[39] Christodoulides, N., Floriano, P.N., Mohanty, S., Dharshan, P., Griffin, M., Lennart, A., et al. (2007) Lab-on-a-Chip Methods for Point of Care Measurements of Salivary Biomarkers of Periodontitis. Annals of the New York Academy of Sciences, 1098, 411-428. http://dx.doi.org/10.1196/annals.1384.035

[40] Christodoulides, N., Mohanty, S., Miller, C.S., Langub, M.C., Floriano, P.N., Dharshan, P., et al. (2005) Application of Microchip Assay System for the Measurement of C-Reactive Protein in Human Saliva. Lab on a Chip, 5, 261-269. http://dx.doi.org/10.1039/b414194f

[41] Christodoulides, N., Floriano, P.N., Sanchez, X., Li, L.Y., Hocquard, K., Patton, A., et al. (2012) Programmable Bio-Nanochip Technology for the Diagnosis of Cardiovascular Disease at the Point of Care. Methodist Debakey Cardiovascular Journal, 8, 6-12. http://dx.doi.org/10.14797/mdcj-8-1-6

[42] Floriano, P.N., Christodoulides, N., Miller, C.S., Ebersole, J.L., Spertus, J., Rose, B.G., et al. (2009) Use of Saliva-Based Nano-Biochip Tests for Acute Myocardial Infarction at the Point of Care: A Feasibility Study. Clinical Chemistry, 55, 1530-1538. http://dx.doi.org/10.1373/clinchem.2008.117713

[43] Vasan, R.S. (2006) Biomarkers of Cardiovascular Disease: Molecular Basis and Practical Considerations. Circulation, 113, 2335-2362. http://dx.doi.org/10.1161/CIRCULATIONAHA.104.482570

[44] Danesh, J., Lewington, S., Thompson, S.G., Lowe, G.D., Collins, R., Kostis, J.B., et al. (2005) Plasma Fibrinogen Level and the Risk of Major Cardiovascular Diseases and Nonvascular Mortality: An Individual Participant MetaAnalysis. JAMA, 294, 1799-1809.

[45] Cushman, M., Lemaitre, R.N., Kuller, L.H., Psaty, B.M., Macy, E.M., Sharrett, A.R., et al. (1999) Fibrinolytic Activation Markers Predict Myocardial Infarction in the Elderly. The Cardiovascular Health Study. Arteriosclerosis, Thrombosis, and Vascular Biology, 19, 493-498. http://dx.doi.org/10.1161/01.ATV.19.3.493

[46] Wang, T.J., Larson, M.G., Levy, D., Benjamin, E.J., Leip, E.P., Omland, T., et al. (2004) Plasma Natriuretic Peptide Levels and the Risk of Cardiovascular Events and Death. New England Journal of Medicine, 350, 655-663. http://dx.doi.org/10.1056/NEJMoa031994

[47] Danesh, J., Wheeler, J.G., Hirschfield, G.M., Eda, S., Eiriksdottir, G., Rumley, A., et al. (2004) C-Reactive Protein and Other Circulating Markers of Inflammation in the Prediction of Coronary Heart Disease. New England Journal of Medicine, 350, 1387-1397. http://dx.doi.org/10.1056/NEJMoa032804

[48] Mangoni, A.A. and Jackson, S.H. (2002) Homocysteine and Cardiovascular Disease: Current Evidence and Future Prospects. The American Journal of Medicine, 112, 556-565. http://dx.doi.org/10.1016/S0002-9343(02)01021-5

[49] Gaspari, M., Cheng, M., Terracciano, R., Liu, X., Nijdam, A.J., Vaccari, L., et al. (2006) Nanoporous Surfaces as 
Harvesting Agents for Mass Spectrometric Analysis of Peptides in Human Plasma. Journal of Proteome Research, 5, 1261-1266. http://dx.doi.org/10.1021/pr050417+

[50] Luchini, A., Geho, D.H., Bishop, B., Tran, D., Xia, C., Dufour, R.L., et al. (2008) Smart Hydrogel Particles: Biomarker Harvesting: One-Step Affinity Purification, Size Exclusion, and Protection against Degradation. Nano Letters, 8, 350-361. http://dx.doi.org/10.1021/nl072174l

[51] Cui, Y., Wei, Q., Park, H. and Lieber, C.M. (2001) Nanowire Nanosensors for Highly Sensitive and Selective Detection of Biological and Chemical Species. Science, 293, 1289-1292. http://dx.doi.org/10.1126/science.1062711

[52] Yang, Z. and Zhou, D.M. (2006) Cardiac Markers and Their Point-of-Care Testing for Diagnosis of Acute Myocardial Infarction. Clinical Biochemistry, 39, 771-780. http://dx.doi.org/10.1016/j.clinbiochem.2006.05.011

[53] Brogan Jr., G.X. and Bock, J.L. (1998) Cardiac Marker Point-of-Care Testing in the Emergency Department and Cardiac Care Unit. Clinical Chemistry, 44, 1865-1869.

[54] Park, J.S., Cho, M.K., Lee, E.J., Ahn, K.Y., Lee, K.E., Jung, J.H., et al. (2009) A Highly Sensitive and Selective Diagnostic Assay Based on Virus Nanoparticles. Nature Nanotechnology, 4, 259-264. http://dx.doi.org/10.1038/nnano.2009.38

[55] Vogt, S., Troitzsch, D., Späth, S. and Moosdorf, R. (2004) Efficacy of Ion-Selective Probes in Early Epicardial in Vivo Detection of Myocardial Ischemia. Physiological Measurement, 25, N21-N26. http://dx.doi.org/10.1088/0967-3334/25/6/N02

[56] Ji, T., Rai, P., Jung, S. and Varadan, V.K. (2008) In Vitro Evaluation of Flexible pH and Potassium Ion-Sensitive Organic Field Effect Transistor Sensors. Applied Physics Letters, 92, Article ID: 233304. http://dx.doi.org/10.1063/1.2936296

[57] Barhoumi, H., Haddad, R., Maaref, A., Bausells, J., Bessueille, F., Léonard, D., et al. (2001) New Technology for Multi-Sensor Silicon Needles for Biomedical Applications. Sensors and Actuators B: Chemical, 78, 279-284. http://dx.doi.org/10.1016/S0925-4005(01)00826-7

[58] Shin, K.H., Moon, C.R., Lee, T.H., Lim, C.H. and Kim, Y.J. (2005) Flexible Wireless Pressure Sensor Module. Sensors and Actuators A, 123-124, 30-35. http://dx.doi.org/10.1016/j.sna.2005.01.008

[59] Kim, J.-H., Heller, D.A., Jin, H., Barone, P.W., Song, C., Zhang, J.Q., et al. (2009) The Rational Design of Nitric Oxide Selectivity in Single-Walled Carbon Nanotube Nearinfrared Fluorescence Sensors for Biological Detection. Nature Chemistry, 1, 473-481. http://dx.doi.org/10.1038/nchem.332

[60] Lammers, T., Kiessling, F., Hennink, W.E. and Storm, G. (2010) Nanotheranostics and Image-Guided Drug Delivery: Current Concepts and Future Directions. Molecular Pharmaceutics, 7, 1899-1912. http://dx.doi.org/10.1021/mp100228v

[61] Barenholz, Y. (2012) Doxil $®$ — The First FDA-Approved Nano-Drug: Lessons Learned. Journal of Controlled Release, 160, 117-134. http://dx.doi.org/10.1016/j.jconrel.2012.03.020

[62] Mufamadi, M.S., Pillay, V., Choonara, Y.E., Du Toit, L.C., Modi, G. and Naidoo, D. (2011) A Review on Composite Liposomal Technologies for Specialized Drug Delivery. Journal of Drug Delivery, 2011, Article ID: 939851. http://dx.doi.org/10.1155/2011/939851

[63] Maurer, N., Fenske, D.B. and Cullis, P.R. (2001) Developments in Liposomal Drug Delivery Systems. Expert Opinion on Biological Therapy, 1, 923-947. http://dx.doi.org/10.1517/14712598.1.6.923

[64] Immordino, M.L., Dosio, F. and Cattel, L. (2006) Stealth Liposomes: Review of the Basic Science, Rationale, and Clinical Applications, Existing and Potential. International Journal of Nanomedicine, 1, 297-315.

[65] Hedman, M., Hartikainen, J. and Syvanne, M. (2003) Safety and Feasibility of Catheter-Based Local Intracoronary Vascular Endothelial Growth Factor Gene Transfer in the Prevention of Postangioplasty and In-Stent Restenosis and in the Treatment of Chronic Myocardial Ischemia: Phase II Results of the Kuopio Angiogenesis Trial (KAT). Circulation, 107, 2677-2683. http://dx.doi.org/10.1161/01.CIR.0000070540.80780.92

[66] Margolis, J., McDonald, J., Heuser, R., Klinke, P., Waksman, R., Virmani, R., et al. (2007) Systemic Nanoparticle Paclitaxel (Nab-Paclitaxel) for In-Stent Restenosis I (SNAPIST-I): A First-in-Human Safety and Dose-Finding Study. Clinical Cardiology, 30, 165-170. http://dx.doi.org/10.1002/clc.20066

[67] McDowell, G., Slevin, M. and Krupinski, J. (2011) Nanotechnology for the Treatment of Coronary in Stent Restenosis: A Clinical Perspective. Vascular Cell, 3, 8. http://dx.doi.org/10.1186/2045-824X-3-8

[68] Zhang, H., Li, N. and Sirish, P. (2012) The Cargo of CRPPR-Conjugated Liposomes Crosses the Intact Murine Cardiac Endothelium. Journal of Controlled Release, 163, 10-17. http://dx.doi.org/10.1016/j.jconrel.2012.06.038

[69] Harel-Adar, T., Ben Mordechai, T., Amsalem, Y., Feinberg, M.S., Leor, J. and Cohen, S. (2011) Modulation of Cardiac Macrophages by Phosphatidylserine-Presenting Liposomes Improves Infarct Repair. Proceedings of the National Academy of Sciences of the United States of America, 108, 1827-1832. http://dx.doi.org/10.1073/pnas.1015623108 
[70] Dvir, T., Bauer, M., Schroeder, A., Tsui, J.H., Anderson, D.G., Langer, R., et al. (2011) Nanoparticles Targeting the Infarcted Heart. Nano Letters, 11, 4411-4444. http://dx.doi.org/10.1021/nl2025882

[71] Lestini, B.J., Sagnella, S.M., Xu, Z., Shive, M.S., Richter, N.J., Jayaseharan, J., et al. (2002) Surface Modification of Liposomes for Selective Cell Targeting in Cardiovascular Drug Delivery. Journal of Controlled Release, 78, 235-247. http://dx.doi.org/10.1016/S0168-3659(01)00505-3

[72] Holland, N.B., Qiu, Y., Ruegsegger, M. and Marchant, R.E. (1998) Biomimetic Engineering of Non-Adhesive Glycocalyx-Like Surfaces Using Oligosaccharide Surfactant Polymers. Nature, 392, 799-801. http://dx.doi.org/10.1038/33894

[73] Zhu, J., Xue, J., Guo, Z., Zhang, L. and Marchant, R.E. (2007) Biomimetic Glycoliposomes as Nanocarriers for Targeting P-Selectin on Activated Platelets. Bioconjugate Chemistry, 18, 1366-1369. http://dx.doi.org/10.1021/bc700212b

[74] Joner, M., Morimoto, K., Kasukawa, H., Steigarwald, K., Meri, S., Nakazawa, G., et al. (2008) Site-Specific Targeting of Nanoparticle Prednisolone Reduces In-Stent Restenosis in a Rabbit Model of Established Atheroma. Arteriosclerosis, Thrombosis, and Vascular Biology, 28, 1960-1966. http://dx.doi.org/10.1161/ATVBAHA.108.170662

[75] Cho, B.H., Park, J.R., Nakamura, M.T., Odintsov, B.M., Wallig, M.A. and Chung, B.H. (2010) Synthetic Dimyristoylphosphatidylcholine Liposomes Assimilating into High-Density Lipoprotein Promote Regression of Atherosclerotic Lesions in Cholesterol-Fed Rabbits. Experimental Biology and Medicine, 235, 1194-1203. http://dx.doi.org/10.1258/ebm.2010.009320

[76] Walton, B.L., Leja, M., Vickers, K.C., Estevez-Fernandez, M., Sanguino, A., Wang, E., et al. (2010) Delivery of Negatively Charged Liposomes into the Atheromas of Watanabe Heritable Hyperlipidemic Rabbits. Vascular Medicine, 15, 307-313. http://dx.doi.org/10.1177/1358863X10374118

[77] Danenberg, H.D., Fishbein, I., Gao, J., Mönkkönen, J., Reich, R., Gati, I., et al. (2002) Macrophage Depletion by Clodronate-Containing Liposomes Reduces Neointimal Formation after Balloon Injury in Rats and Rabbits. Circulation, 106, 599-605. http://dx.doi.org/10.1161/01.CIR.0000023532.98469.48

[78] Buxton, D.B. (2009) Nanomedicine for the Management of Lung and Blood Diseases. Nanomedicine, 4, 331-339. http://dx.doi.org/10.2217/nnm.09.8

[79] Cyrus, T., Zhang, H., Allen, J.S., Williams, T.A., Hu, G., Caruthers, S.D., et al. (2008) Intramural Delivery of Rapamycin with Alphavbeta3-Targeted Paramagnetic Nanoparticles Inhibits Stenosis after Balloon Injury. Arteriosclerosis, Thrombosis, and Vascular Biology, 28, 820-826. http://dx.doi.org/10.1161/ATVBAHA.107.156281

[80] Winter, P.M., Caruthers, S.D., Zhang, H., Williams, T.A., Wickline, S.A. and Lanza, G.M. (2008) Antiangiogenic Synergism of Integrin-Targeted Fumagillin Nanoparticles and Atorvastatin in Atherosclerosis. JACC: Cardiovascular Imaging, 1, 624-634. http://dx.doi.org/10.1016/j.jcmg.2008.06.003

[81] Winter, P.M., Neubauer, A.M., Caruthers, S.D., Harris, T.D., Robertson, J.D., Williams, T.A., et al. (2006) Endothelial Alpha(v)Beta3 Integrin-Targeted Fumagillin Nanoparticles Inhibit Angiogenesis in Atherosclerosis. Arteriosclerosis, Thrombosis, and Vascular Biology, 26, 2103-2109. http://dx.doi.org/10.1161/01.ATV.0000235724.11299.76

[82] Hoffmann, R., Mintz, G.S., Dussaillant, G.R., Popma, J.J., Pichard, A.D., Satler, L.F., et al. (1996) Patterns and Mechanisms of In-Stent Restenosis. A Serial Intravascular Ultrasound Study. Circulation, 94, 1247-1254. http://dx.doi.org/10.1161/01.CIR.94.6.1247

[83] Samaroo, H.D., Lu, J. and Webster, T.J. (2008) Enhanced Endothelial Cell Density on NiTi Surfaces with Sub-Micron to Nanometer Roughness. International Journal of Nanomedicine, 3, 75-82.

[84] Kastrati, A., Mehilli, J., Pache, J., Kaiser, C., Valgimigli, M., Kelbaek, H., et al. (2007) Analysis of 14 Trials Comparing Sirolimus-Eluting Stents with Bare-Metal Stents. New England Journal of Medicine, 356, 1030-1039. http://dx.doi.org/10.1056/NEJMoa067484

[85] Lagerqvist, B., James, S.K., Stenestrand, U., Lindbäck, J., Nilsson, T., Wallentin, L., et al. (2007) Long-Term Outcomes with Drug-Eluting Stents versus Bare-Metal Stents in Sweden. New England Journal of Medicine, 356, 10091019. http://dx.doi.org/10.1056/NEJMoa067722

[86] Mauri, L., Hsieh, W.H., Massaro, J.M., Ho, K.K., D’Agostino, R. and Cutlip, D.E. (2007) Stent Thrombosis in Randomized Clinical Trials of Drug-Eluting Stents. New England Journal of Medicine, 356, 1020-1029. http://dx.doi.org/10.1056/NEJMoa067731

[87] Stone, G.W., Moses, J.W., Ellis, S.G., Schofer, J., Dawkins, K.D., Morice, M.C., et al. (2007) Safety and Efficacy of Sirolimus- and Paclitaxel-Eluting Coronary Stents. New England Journal of Medicine, 356, 998-1008. http://dx.doi.org/10.1056/NEJMoa067193

[88] Wieneke, H., Dirsch, O., Sawitowski, T., Gu, Y.L., Brauer, H., Dahmen, U., et al. (2003) Synergistic Effects of a Novel Nanoporous Stent Coating and Tacrolimus on Intima Proliferation in Rabbits. Catheterization and Cardiovascular Interventions, 60, 399-407. http://dx.doi.org/10.1002/ccd.10664

[89] Bhargava, B., Reddy, N.K., Karthikeyan, G., Raju, R., Mishra, S., Singh, S., et al. (2006) A Novel Paclitaxel-Eluting 
Porous Carbon-Carbon Nanoparticle Coated, Nonpolymeric Cobalt-Chromium Stent: Evaluation in a Porcine Model. Catheterization and Cardiovascular Interventions, 67, 698-702. http://dx.doi.org/10.1002/ccd.20698

[90] Ayon, A.A., Cantu, M., Chava, K., Agrawal, C.M., Feldman, M.D., Johnson, D., et al. (2006) Drug Loading of Nanoporous $\mathrm{TiO}_{2}$ Films. Biomedical Materials, 1, L11-L15. http://dx.doi.org/10.1088/1748-6041/1/4/L01

[91] Liu, D.M., Yang, Q. and Troczynski, T. (2002) Sol-Gel Hydroxyapatite Coatings on Stainless Steel Substrates. Biomaterials, 23, 691-698. http://dx.doi.org/10.1016/S0142-9612(01)00157-0

[92] Caves, J.M. and Chaikof, E.L. (2006) The Evolving Impact of Microfabrication and Nanotechnology on Stent Design. Journal of Vascular Surgery, 44, 1363-1368. http://dx.doi.org/10.1016/j.jvs.2006.08.046 